\title{
Indignados en España e Indecisos en Polonia. La inspiración española en el contexto polaco y el fracaso de la protesta en el país de "Solidarnosć"
}

\author{
Karolina Golemo* \\ Recibido: mayo 20 de 2014 - Aceptado: septiembre 13 de 2014
}

\begin{abstract}
Resumen
El movimiento $15 \mathrm{M}$ creado en primavera de 2011 y la actividad social de los Indignados en España fue un fenómeno sociocultural que suscitó un gran interés no solo en la sociedad española sino también en otros países de Europa y de América. Parece que el movimiento de Indignados originario de España inspiró también a una parte de jóvenes polacos a rebelarse contra el Gobierno. Pero el carácter y la dimensión de esas protestas fueron visiblemente diferentes de lo que ocurría en la Vieja Europa. El objetivo del texto será evidenciar las semejanzas y los contrastes en la actitud de los jóvenes en España y en Polonia, haciendo referencia a los comentarios de la prensa polaca.
\end{abstract}

Palabras clave: Indignados, Polonia, España, movimiento social, protestas

\footnotetext{
* Instituto de Estudios Interculturales, Universidad Jagelónica de Cracovia. Correo: karolina.golemo@uj. edu.pl
} 


\title{
Indignants in Spain and Indecisive in Poland. The Spanish Inspiration in the Polish Context and the Protest Failure in the Country of "Solidarnosć"
}

\begin{abstract}
The 15-M movement raised in Spring 2011 and the social activity of the Indignants in Spain was a social and cultural phenomenon of big interest not only in the Spanish society but also in other countries of Europe and America. It seems that the Indignants Movement -that was started in Spain- was also the inspiration for a segment of Polish youth to protest against the Government. But the nature and the scope of these protests were clearly different from it was happening in Old Europe. The objective of this article is to show similarities and differences of the young people's attitude in Spain and Poland, making reference to comments of the Polish press.
\end{abstract}

Key words: Indignants; Poland; Spain; social movement; protests. 
El movimiento M15, aparecido en la primavera de 2011, y la actividad social de los Indignados en España es un fenómeno socio-cultural que ha suscitado un gran interés no solo en la sociedad española, sino también en otros países de Europa y de América (cf. Feixa-Nofre, 2013, passim). Las protestas de los jóvenes han sido abordadas por varios analistas políticos, periodistas y sociólogos, que las definen como ejemplos de "nuevos movimientos sociales" y movilizaciones ciudadanas surgidas espontáneamente, desde abajo. Al debate sobre ese movimiento transnacional se unieron varios intelectuales y artistas (como Stéphane Hessel, Leo Bassi, Zygmunt Bauman o Toni Gatlif, autor de la película "Indignados").

En los últimos años de recesión socio-económica se hace referencia a Polonia como uno de los Estados comunitarios menos afectados por la crisis. Los indicadores "duros" evidencian una situación relativamente buena en comparación con otros países del oeste de Europa. No obstante, los ciudadanos polacos, y en particular la generación de jóvenes, están enfrentándose a diferentes obstáculos derivados de la recesión global (dificultades en el mercado de trabajo, aumento de los precios de los alimentos, subida en los gastos cotidianos, la desproporción de precios y de estipendios en comparación con los sueldos en los países occidentales europeos).

Parece que el movimiento de Indignados, originario de España, inspiró también a una parte de jóvenes polacos a rebelarse contra el Gobierno. Pero el carácter y la dimensión de esas protestas fueron visiblemente diferentes a lo que ocurría en la Vieja Europa. El objetivo de este articulo será el de presentar Ruch Oburzonych, o sea, el movimiento de los jóvenes indignados polacos, mostrar las principales semejanzas y los contrastes existentes entre la actitud de los jóvenes en España y en Polonia, y, además, analizar las causas de la poca repercusión de la iniciativa polaca a través de algunos comentarios de la prensa'.

\section{Movimientos sociales como una manifestación del descontento cívico}

En el campo de ciencias sociales existen numerosos enfoques e interpretaciones para describir el fenómeno de movimientos sociales. Entre tipologías y dimensiones analíticas diferentes destacan las de Immanuel Wallerstein, Alain Touraine, Clauss Offe, Manuel Castells o los estudios de los sociólogos polacos Zygmunt Bauman, Piotr Sztompka y Tadeusz Paleczny². Según el Diccionario de las ciencias sociales oxfordiano, el movimiento

1 Fueron analizados 35 artículos de prensa polaca provenientes de los siguientes periódicos, semanarios y páginas web: "Gazeta Wyborcza", "Rzeczpospolita", "Newsweek", "Fakt", "Tok FM", "Krytyka Polityczna", salon24.pl. Los medios de comunicación escogidos por el análisis representan diferentes corrientes de opinión: algunos de derecha y otros de izquierda, o de posición "central". El análisis del contenido fue cualitativo y la muestra no fue representativa. Por tanto, los resultados pueden servir exclusivamente como ejemplificación de algunas opiniones e ideas. Las palabras clave utilizadas para determinar la muestra: "Indignados polacos", "jóvenes indignados polacos", "Indignados en Polonia", "Movimiento de Indignados polacos". Periodo: octubre 2011 (fueron añadidos algunos comentarios posteriores).

2 Este artículo no tiene como objetivo principal presentar diferentes enfoques teoréticos. Está concentrado en el análisis cualitativo de la prensa polaca. Duke University Press 2004; A. Touraine, Solidarité - Analyse d'un mouvement social - Pologne 1980-1981. Paris: Fayard 1982; A. Touraine, Un nouveau paradigme. Pour comprendre le monde aujourd'hui, Librairie Arthème Fayard, Paris 2005; P. Sztompka, Ruchy społeczne - struktury in 
social es un "esfuerzo organizado de un grupo considerable de personas intencionado a cambiar (o contrastar un cambio) de un determinado aspecto de la sociedad"3. Tadeusz Paleczny (2010), el autor de la monografía sobre nuevos movimientos sociales, constata que son, en primer lugar, una forma de defenderse de las reglas de la vida social que limitan a los individuos, los manipulan y los hacen depender de la organización del sistema. Los movimientos sociales son, además, una "oportunidad para crear y formar nuevos mecanismos de vida colectiva basados en participación espontánea y voluntaria y en una actividad consciente" (Paleczny 2010, 7).

Movimientos sociales contemporáneos sirven de contrapeso para las instituciones gubernamentales y organizaciones sociales que a menudo manifiestan insuficiencias funcionales, especialmente en épocas de crisis. La participación en los movimientos surge entonces de la actitud contestataria y permite la inclusión y la actuación en la esfera pública. Puede ser también un resultado de las transformaciones de identidad que conducen a mejorar la conciencia de las propias necesidades. El comprometerse en movimientos sociales implica el aumento de la responsabilidad ciudadana y del sentimiento de subjetividad y, en consecuencia, comporta una disposición a actuar para bienes comunes y no solo objetivos individuales (Paleczny 2010, 7). Relacionar las propias acciones con las actividades de un movimiento social significa obtener una posibilidad de una articulación más fuerte y más expresiva de las propias tendencias y expectativas, y del proprio sistema de valores. Solamente a fuerza de acciones colectivas es posible atravesar el esqueleto duro del aparato estatal y administrativo, y abrirse paso para alcanzar un lugar nuevo en el espacio ciudadano. Resumiendo varias definiciones del movimiento social se pueden individuar algunos elementos constitutivos: un grupo de personas, la organización y métodos de actuar, tendencia al cambio social como el objetivo principal para conseguir, aparición de una identidad colectiva que supera iniciativas singulares (Paleczny 2010, 15; Della Porta y Diani 2009, 25).

Los movimientos sociales pueden ser respuesta a los desafíos de la globalización. Manuel Castells (2009), en sus análisis de la sociedad red, pone atención a la coincidencia de dos fuerzas que se influencian recíprocamente condicionando la vida de la gente. Por un lado, procesos de globalización, progresiva universalización y cosmopolitización del mundo, y por otro lado, el poder de la identidad (cultural, étnica, local), especialmente en su dimensión colectiva. Vivimos en la época de la expansión de cuestiones relacionadas con la identidad que se contraponen a las tendencias "globalizantes": varios grupos (étnicos, religiosos, sociales) resaltan su unicidad y excepcionalidad cultural. La gente intenta tomar el control de su vida y de su ambiente más cercano. Los movimientos sociales que luchan por la autonomía cultural y por la subjetividad de comunidades locales son una expresión de las identidades colectivas fuertes. Las reacciones "anti-globalización"

statu nascendi. En : P. Sztompka-M. Kucia (eds.) Socjologia. Lektury. Kraków: Znak 2007; C. Offe, Partidos Políticos y nuevos movimientos sociales. Madrid: Editorial Sistema1996. M. Castells, The Power of Identity: The Information Age: Economy, Society, and Culture Volume II. Chichester: Wiley-Blackwell 2009, T. Paleczny, Nowe ruchy spoteczne. Kraków: Wydawnictwo Uniwersytetu Jagiellońskiego 2010.

3 Słownik socjologii i nauk społecznych. Warszawa: PWN 2008, p. 292. 
significan una resistencia contra la desagregación de vínculos sociales y tradicionales sistemas de valores. Los movimientos sociales que surgen dentro del espacio delineado por la sociedad cívica logran contrastar la globalización de diferentes maneras. Pueden tener un carácter renovador o conservador. Todos están unidos por un objetivo principal: defender, construir o reconstruir y mantener la identidad de una comunidad. Castells enumera tres tipos de identidad: legitimadora, de resistencia y la identidad proyecto, que tienen cada una sus propias dinámicas (Castells, 2009, passim). El análisis del movimiento de los Indignados conlleva a reflexionar sobre dos: identidad de resistencia e identidad de proyecto. El primer tipo nace de una contestación, oposición de la gente a los cambios emergentes. Las identidades de resistencia se rebelan contra la destrucción del orden tradicionalmente consolidado, contra la deconstrucción de vínculos sociales y los sistemas de normas y valores afirmados en la sociedad. Movimientos sociales que se crean con base en este tipo de identidad pueden tomar varias formas y funcionar como movimientos etnocéntricos conservadores, nacionalistas o, bien, fundamentalistas. Pero caben dentro esta categoría también movimientos de liberación, de emancipación, de igualdad, que valorizan a un grupo socio-cultural, étnico, etc. Todos estos movimientos se oponen a las tendencias provocadas por la globalización. Tadeusz Paleczny afirma que los movimientos de resistencia "surgen a partir de la protección de valores existentes, (...) de relaciones fundadas en el sentimiento de comunidad, en contra de las normas corporativas y sociales ${ }^{4}$ introducidas junto al nuevo orden social postmoderno" (Paleczny 2010, 49). El movimiento de los Indignados puede ser visto, en una cierta manera, bajo esta óptica. Sin embargo, en la clasificación de este fenómeno pueden presentarse algunas dudas, por ejemplo: ¿pueden los protestantes en diferentes lugares de España (y del mundo) definirse como una comunidad? ¿Tienen realmente un sentido de la unidad y un sistema de valores común? ¿Bajo qué concepto se identifican recíprocamente? La observación de este movimiento conduce a la conclusión de que es más bien un grupo heterogéneo que une a las personas provenientes de varios ambientes. Se les nota la visible actitud favorable a Internet, al ambiente digital y a las acciones en la red (virtuales). La iniciativa de los Indignados fue incluso definida como "ciberactivismo" (Chueca 2011, 59). Algunos autores que analizan el fenómeno de movimientos sociales preguntan si en la época del desarrollo tecnológico aún existe la necesidad de crear los "vínculos de identidad" en función de experiencias comunes directas e interacciones "reales" (Della Porta y Diani 2009, 147). Los Indignados optaron por servicios de red social como principales instrumentos de comunicación. Una parte importante de su interacción, tanto entre ellos como con el mundo "externo", tuvo lugar en el espacio virtual. Utilizaron los logros de ciencia y de tecnología -como Facebook, Twitter, tv digital, blogs u otras herramientas digitales-, que son emblemáticos para la época de la globalización actual ${ }^{5}$. Es muy probable que los jóvenes

$4 \quad$ En referencia a la división entre comunidad y sociedad elaboradas por Ferdinand Tönnies en su obra "Gemeinschaft und Gesellschaft" de 1887.

5 Vale la pena recordar que, como paradoja, los movimientos sociales modernos (hasta los más "conservadores") funcionan dentro de la "sociedad red", comunicándose a través varios herramientas multimedias. Entonces, para combatir los efectos negativos de la globalización hacen uso de los instrumentos que ella misma aportó (cf. Paleczny 2010, 50). 
hayan escogido sus nuevos medios de comunicación y nuevos modos de debate ante la falta de credibilidad, de representatividad y de empatía de los medios de comunicación tradicionales (Fernández-Planells 2013, 111), y no solo por el motivo práctico (intercambio de informaciones más rápido y multidimensional).

Los movimientos sociales que emergen de las identidades de proyecto se destacan por ser innovadores, dinámicos y progresistas. En vez de soluciones extremistas proponen una transformación del Estado nacional y un mejoramiento de su funcionamiento en una situación de continuo antagonismo de diferentes tendencias contrastantes. La identidad de proyecto se expresa, antes de nada, a través de movimientos alterglobalizadores, ecológicos, feministas, o aquellos que luchan por derechos de minorías sexuales. Los alterglobalistas se ponen como objeto la "introducción de un control ciudadano, de abajo, de los procesos de desarrollo económico y político en el mundo (...)" (Paleczny, 2010, 50). Se puede considerar que la iniciativa de los Indignados cabe también dentro esta categoría. Los protestantes que funcionan en las "sociedades red" contemporáneas se organizan gracias a varios fórum de opiniones que juntan a las personas de diferentes ambientes locales; se unen por un objetivo común, aunque bastante complejo, y no siempre bien articulado. Este propósito que les une tiene una dimensión intercultural: luchar por el reconocimiento de su subjetividad, el derecho a la vida digna con un nivel satisfactorio (no solo en el aspecto material), por la realización de sus aspiraciones profesionales y expectativas sobre su desarrollo personal. Como subraya Touraine, la época de globalización se destaca por la circulación acelerada de bienes y de servicios, pero también de prácticas culturales, representaciones sociales y políticas (Touraine 2008, 55). La internacionalización del concepto de "indignación" produjo algunas de sus variantes locales con características diferentes, de las cuales el modelo polaco puede ser un ejemplo.

\section{Indignados en salsa polaca. Convenio del 15 Octubre}

El movimiento de los Indignados en Polonia surgió gracias a una iniciativa de los jóvenes varsovianos del Instituto Humanístico Multicultural, todos de edad entre 15 y 19 años. En otoño de 2011, algunos meses después del inicio de la famosa Acampada de Sol en Madrid, crearon el Convenio del 15 Octubre [Porozumienie 15 Października] ${ }^{6} \mathrm{y}$ organizaron una manifestación en Varsovia, una de las miles de protestas que tuvieron lugar ese día en diferentes partes del mundo y que se juntaron bajo el eslogan común "Unidos por un Cambio Global" (Toscano 2013, 85). Los jóvenes indignados polacos escribieron también una carta al presidente y al premier de Polonia.

En su página web, entonces activa, presentaron las "21 demandas", explicando sus expectativas y su ideología. En ese proyecto destacó una visible asociación con las

6 La página web http://15pazdziernika.pl/ creada con ocasión de la protesta del 15 octubre 2011 ya no es accesible. Existe aún la cuenta en Facebook que recuerda esa iniciativa "Solidarios con España - Convenio del 15 Octubre" (en polaco: "Solidarni z Hiszpanią - Porozumienie 15 Października"). El nombre de este proyecto revela dos puntos de referencia: una visible inspiración española y un recuerdo de las protestas de Solidarność de los años 80 del siglo XX, cfr. https://www.facebook.com/ Porozumieniel5 [acceso: 4.01.2014]. 
21 demandas del movimiento de los trabajadores del Astillero de Gdańsk que luego se transformó en Solidarność, presentadas en agosto de 19807. Al mismo tiempo, observando la iniciativa de los Indignados polacos se notaba una referencia al Movimiento 15M de España y a su Manifiesto 15M (Cf. Nofre 2013, 28-35). Los requerimientos de los polacos recordaban algunas reclamaciones de los Indignados españoles: se constataba que todos tienen derecho a una vida feliz y digna, el Estado debe preocuparse de sus ciudadanos en vez de alejarse de ellos. Las autoridades deben proveer a los ciudadanos de las oportunidades e instrumentos que ayuden a realizar sus objetivos. Los polacos anunciaban: "No queremos depender de las grandes corporaciones ni de las elites financieras. Queremos un acceso libre a la educación y a la cultura. No queremos ser tratados como "mercadería", por un lado, y percibidos solamente como "consumidores", por otro.

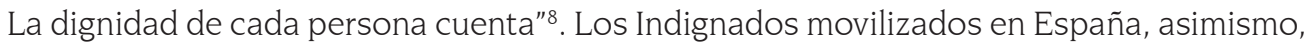
hablaban de la necesidad de la Revolución Ética: "Hemos puesto el dinero por encima del Ser Humano y tenemos que ponerlo a nuestro servicio" (Manifiesto.... 2011, 85). El manifiesto de los Indignados polacos (las 21 demandas) concluía con las palabras: "ipor todo lo anterior, expresamos nuestro descontento e indignación!". En el Manifiesto 15M la última frase sonaba de manera similar, aunque más concisa: "Por todo lo anterior, estoy indignado" (Manifiesto... 2011, 85). La siguiente tabla muestra algunos de las principales reclamaciones es de los Indignados polacos y españoles:

Tabla 1. Reclamaciones de los Indignados en Polonia y en España - algunos ejemplos

\begin{tabular}{|c|c|}
\hline España & Polonia \\
\hline $\begin{array}{l}\text { Mejorar el sistema democrático } \\
\text { Promover una democracia más participativa } \\
\text { Liquidar el bipartidismo PSOE-PP } \\
\text { Terminar con del dominio de los bancos y de las } \\
\text { corporaciones financieras } \\
\text { Introducir una "auténtica división de poderes" } \\
\text { Movilización ciudadana }\end{array}$ & $\begin{array}{l}\text { Parar el aumento de los impuestos para las } \\
\text { personas más pobres } \\
\text { La responsabilidad por la crisis debe ser de } \\
\text { los bancos y de las corporaciones y no de los } \\
\text { "ciudadanos de a pie" } \\
\text { Cantidad suficiente de plazas gratuitas en las } \\
\text { guarderías y jardines de infancia } \\
\text { Baja por maternidad (y paternidad) de } 3 \text { años, } \\
\text { integramente pagada }\end{array}$ \\
\hline
\end{tabular}

$7 \quad$ El día 17 de agosto el Comité de Coordinación de Huelga (Międzyzakładowy Komitet Strajkowy MKS) presentó al gobierno las 21 demandas en las que se pedía, entre otras cosas, la creación de sindicatos libres, la observación de los derechos y libertades garantizadas por la Constitución y el mejoramiento de la situación existencial de los polacos. En septiembre del mismo año el Comité de Coordinación de Huelga se legalizó como Comité de Coordinación Nacional del Sindicato Libre Solidarność, y Lech Wałęsa fue elegido su presidente.

$8 \quad$ Cf. artículo en la página web de los Jóvenes Socialistas polacos: Popieramy postulaty Oburzonych lonlinel, http:// www.mlodzisocjalisci.pl/pl/Wiadomosci/772,Popieramy-postulaty-Oburzonych lacceso: 4.01.2014] 


\begin{tabular}{|l|l|}
\hline \multicolumn{1}{|c|}{ España } & \multicolumn{1}{c|}{ Polonia } \\
\hline Rechazo y condena de la corrupción & $\begin{array}{l}\text { Acceso al sistema de la asistencia sanitaria } \\
\text { y tratamientos en los hospitales gratuitos para } \\
\text { todos } \\
\begin{array}{l}\text { Acceso popular a los medios de comunicación } \\
\text { que deberán ser éticos y precisos (veraces) }\end{array}\end{array}$ \\
$\begin{array}{l}\text { Terminar con los recortes presupuestarios en la } \\
\text { educación, con el plan Bolonia y con el aumento } \\
\text { de las tasas universitarias }\end{array}$ & $\begin{array}{l}\text { Asistencia social gratuita para las personas con } \\
\text { necesidades (ancianos, discapacitados) } \\
\text { Renunciar al sistema educativo de Bolonia (Pro- } \\
\text { ceso de Bolonia) } \\
\text { Parar de subir más la edad de jubilación }\end{array}$ \\
\hline
\end{tabular}

Fuente: elaboración propia a partir de artículos de prensa (española y polaca) y páginas web de la Democracia Real Ya y Movimiento 15M

Parece interesante subrayar que en las 21 Demandas de los polacos fueron incluidas también reclamaciones que no tenían nada a que ver con la crisis socio-económica, pero que sí estaban relacionadas con la esfera de costumbres. Los jóvenes demandaban poner un impuesto a la Iglesia católica, incluir la educación sexual en el programa escolar, introducir clases de Filosofía en lugar de clases de Religión en las escuelas. Además, los iniciadores de la protesta reivindicaban que los anticonceptivos fueran pagados con el presupuesto del Estado y pedían el rembolso de los gastos para la píldora anticonceptiva. Exigieron que el aborto fuese legal y que dependiera de la decisión de la mujer embarazada $^{9}$. Además, pidieron que fuera introducida la institución de parejas de hecho tanto heterosexuales como homosexuales. Uno de las reclamaciones más curiosas fue el de hacer pública la investigación sobre cárceles secretas de la CIA en territorio polaco ${ }^{10}$. Pueden extrañar estos requerimientos, muy poco relacionados con la recesión y la condición socio-económica de los jóvenes. ¿Por qué los jóvenes polacos demandaban la limitación del papel de la Iglesia y la legalización completa del aborto? Probablemente el motivo está en la convicción de que haciéndolo la sociedad polaca "se acercaría a Europa". Tal vez sea una medida simbólica para sentirse más europeos y desarrollados. Esta demanda obviamente no resuelve problemas de los jóvenes, pero crea la sensación ilusoria de que tenemos unos estándares "occidentales" (Cf. Karoń, 2011).

La iniciativa de los alumnos del Instituto Humanístico no fue la única: en paralelo, el 27 de octubre de 2011 apareció un Manifiesto de los Indignados [Manifest Oburzonych] en Facebook, creado por el Movimiento de los Indignados Polacos [Polski Ruch Oburzonych], en el que se podía leer: "La economía mundial debe basarse en la «Teoría 3R»: introducción de los cambios Radicales, Racionales y Reales fundados en la tesis: 'El dinero debe dejar de ser la mercadería'. Eso significa: dejar de contar intereses de las cuotas depositadas y de

\footnotetext{
9 Según los jóvenes, en caso de violencia o de peligro para la mujer, el aborto debería ser financiado por el estado.

10 Donde se habrán retenido y torturado los presuntos terroristas, en el periodo 2003-2005, cf. La cárcel de la CIA en Polonia: ¿un secreto a gritos?, http://actualidad.rt.com/actualidad/view/41200-La-carcel-deCIA-en-Polonia-un-secreto-a-gritos [acceso 4.01.2014]
} 
los créditos". El texto del manifiesto, focalizado solamente sobre cuestiones económicas y financieras, terminaba con la frase: "Llamamos al Gobierno a que resigne de la defensa de los privilegios del $1 \%$ de la población. Protejan la mayoría - iestad con nosotros!"”1.

\section{La protesta del 15 octubre. Un fracaso de la indignación polaca}

El día 15 de octubre de 2011 en cerca de 950 ciudades de 82 países del mundo fueron organizadas protestas y manifestaciones relacionadas con el tema de la "indignación" de las personas excluidas por el sistema. Los Indignados polacos se reunieron en la puerta de la Universidad de Varsovia. Luego pasaron a lo largo de los edificios del Ministerio de Hacienda, Banca Nacional Polaca, oficina de la Comisión Europea en Varsovia, la Bolsa, la cancillería del premier. Sus objetivos principales indicados por ellos mismos se podían resumir en los eslóganes siguientes: mejorar la democracia, mejorar la situación de los más discriminados, comenzar un debate. En las protestas se comprometieron algunos políticos de la izquierda polaca (SLD, Alianza de Izquierda Democrática) y Movimiento Palikot (RP "izquierda populista") ${ }^{12}$. Participaron también representantes del "Movimiento de los inquilinos de las casas sociales", protestando contra el aumento de los gastos y contra las expulsiones. Se juntaron, asimismo, jóvenes de la iniciativa "GMO-no es bueno" que querían prestar atención al empeoramiento de la calidad de la vida humana. Hubo también representantes de un movimiento contra las vacunaciones, con un eslogan: "Dejen de experimentar con la sociedad polaca. Vacunaciones - hechos escondidos", sugiriendo que el programa de vacunaciones obligatorias fuera un resultado de una manipulación de la sociedad por parte del Gobierno y que sirviera solo para complacer a un lobby de productores.

A los varsovianos se unieron tres chicos españoles que habían ocupado la Puerta del Sol en Madrid. Según comentarios de los observadores de la marcha, su presencia funcionó como un "ennoblecimiento", un valor adjunto para la manifestación. Los españoles, al inicio de la manifestación, leyeron una letra destinada a los compañeros polacos, en que constataron: "lo más importante es despertar la consciencia social, liberarse del miedo de lo que está ocurriendo y adquirir una fuerza para luchar contra la injusticia y contra el abuso" (Dąbrowski, 2011). En las protestas en España tomaron parte no solo jóvenes, sino también jubilados, personas en paro y toda la gente descontenta con sus condiciones de trabajo. En Varsovia participaron principalmente los alumnos del instituto y los estudiantes. Según los policías la cantidad de los manifestantes no superó las 150 personas, mientras que los organizadores indicaban una cifra más alta: 800 (PAP, 2011).

11 Cf. https://www.facebook.com/pages/Polski-Ruch-Oburzonych/234123983315508?fref=ts El día 4 de enero del 2014, o sea, más de 2 años después de su creación, la página tenía solamente 23 seguidores.

12 Sobre la aparición y el desarrollo del Movimiento Palikot (actualmente tiene un nombre nuevo: "Tu Movimiento") cf. Karolina Golemo, Entre poder y espectáculo. Nuevas dimensiones de la cultura política en Polonia. En: Materiales de las IV Jornadas Científicas de la Difusión de la Investigación, marzo 2012, Universidad Castilla La Mancha, Cuenca (de próxima publicación). 
En las comunicaciones mediáticas sobre el evento destacaba una atmósfera del pique-nique. Los protestantes debatían comiendo bocadillos y escuchando música. Se organizaron proyecciones de películas, se distribuía comida gratuita ${ }^{13}$. Se manifestaron pocas personas, pero los participantes dijeron con convicción: "Hablamos a nombre de 30 millones" (Opolska, 2011), aunque los comentadores se preguntasen de dónde salía exactamente esta cifra. Los lemas polacos se parecían a aquellos de sus compañeros españoles. Comprobaban que el poder sirve solamente a las élites y no a los ciudadanos. Sus deseos fueron los de tener más influencia sobre la política del Estado, que no se limite a la participación "simbólica" en las elecciones generales cada cuatro años. Los jóvenes polacos, tal y como los españoles, demostraron que las autoridades no los representan, estando ocupados con sus conflictos internos. Con una visible referencia al "modelo español" demandaban que durante la marcha se discutieran las 21 Demandas y todos los otros problemas que afectan a la gente. Los jóvenes polacos sabían bien por qué protestaban ("El sistema no nos representa"), pero al igual que los Indignados de España no tenían respuestas ni soluciones concretas. A la pregunta "¿Cómo queréis cambiar la situación?" contestaban de modo evasivo: "No sabemos. Esperamos que haya una discusión" (Konarski, 2011). Algunos meses después, en mayo de 2012 algunas decenas de los indignados volvieron a la protesta en el centro de Varsovia: la prensa y la televisión polacas mostraban el campamento de los indignados polacos, con tiendas de campaña, colchones inflables y sillas de camping. Los mismos jóvenes llamaron a su acción "Ocupación de Varsovia"; en las entrevistas hablaban de la "toma del mando de la ciudad". Protestaban contra expulsiones de las casas de las personas pobres que no consiguen pagar los gastos, contratos basura, falta de la influencia de los ciudadanos sobre las autoridades. Uno de los jóvenes dijo al periodista: "Se gastan millardos de zloty para construir los estadios de futbol [una alusión a la inversión hecha en ocasión de la Euro Copa-K. G.], pero falta el dinero para las guarderías, comedores, casas municipales..." (Karpieszuk, 2012).

En la iniciativa polaca destacaron algunos momentos de énfasis y fatuidad. Por ejemplo, una joven representante de los Indignados, que no sabía exponer concretamente sus expectativas durante una entrevista en la radio Tok Fm, dijo de manera grandilocuente: "se acerca una gran revolución, y el trabajo no será tan importante como ahora" (Górecki, 2011). Un participante de la marcha varsoviana declaró: "El mundo se encantó con el capital, tomó como modelo el capitalismo, olvidándose de la dignidad humana. Hoy en día es el mítico libre mercado el que dicta las condiciones. Y nosotros queremos que el ser humano esté en el primer lugar" (Janiszewski, 2011). En comparación con los lemas visibles durante las manifestaciones en España, en Polonia no apareció tan visiblemente el problema de la corrupción de los políticos.

13 No era un repertorio de actividades y facilitaciones tan desarrollado como aquel de la Acampada de Sol donde funcionaron: biblioteca, espacios para practicar yoga y reiky, incluso una enfermería que repartía crema solar (cf. Toscano 2011, 83). 
Indignados en España e Indecisos en Polonia. La inspiración española en el contexto polaco y el fracaso de la protesta ...

Tabla 2. Lemas de los Indignados españoles y polacos - algunos ejemplos

\begin{tabular}{|l|l|}
\hline \multicolumn{1}{|c|}{ España } & \multicolumn{1}{c|}{ Polonia } \\
\hline "No somos marionetas/mercancía en & "Ignora los medios de comunicación, aprende por tu cuenta" \\
manos de políticos y banqueros" & "Queremos casas y no créditos" \\
"Democracia real iYA!» & "No bailes al son que toquen" \\
"¿Demócrata? iNo te calles! iA la calle!" & "España, estamos con vosotros" \\
"Hartos, sin pan" & "Stop a la tiranía del mercado" \\
"Escuchad la ira del pueblo" & "Nadie se esperaba una revolución polaca" \\
"Contra el Pacto del Euro y contra la crisis & "Poder en los manos del pueblo" \\
y el capital" & "El pueblo unido jamás será vencido" \\
"Nos habéis dejado sin nada, ahora & "iEl capital humano dice basta!" \\
lo queremos todo" & "Nosotros pagamos por vuestra crisis" "Vuestros errores, \\
"El enemigo no viene en patera, \\
viene en limusina" & nuestra pasta" \\
"Pienso, no sirvo" & "Democracia ya para nosotros" \\
"Si no nos dejáis soñar, no os deja- & "Nuestras autoridades nos traicionan continuamente" \\
remos dormir" & "Nuestra vida es un valor" \\
& "Capitalismo - eso se puede curar" \\
& "Fascistas, burgueses. Se está acercando vuestro fin". \\
\hline
\end{tabular}

Fuente: elaboración propia a partir de diferentes artículos de prensa (española y polaca) y fotos hechas durante las manifestaciones, publicadas en Internet

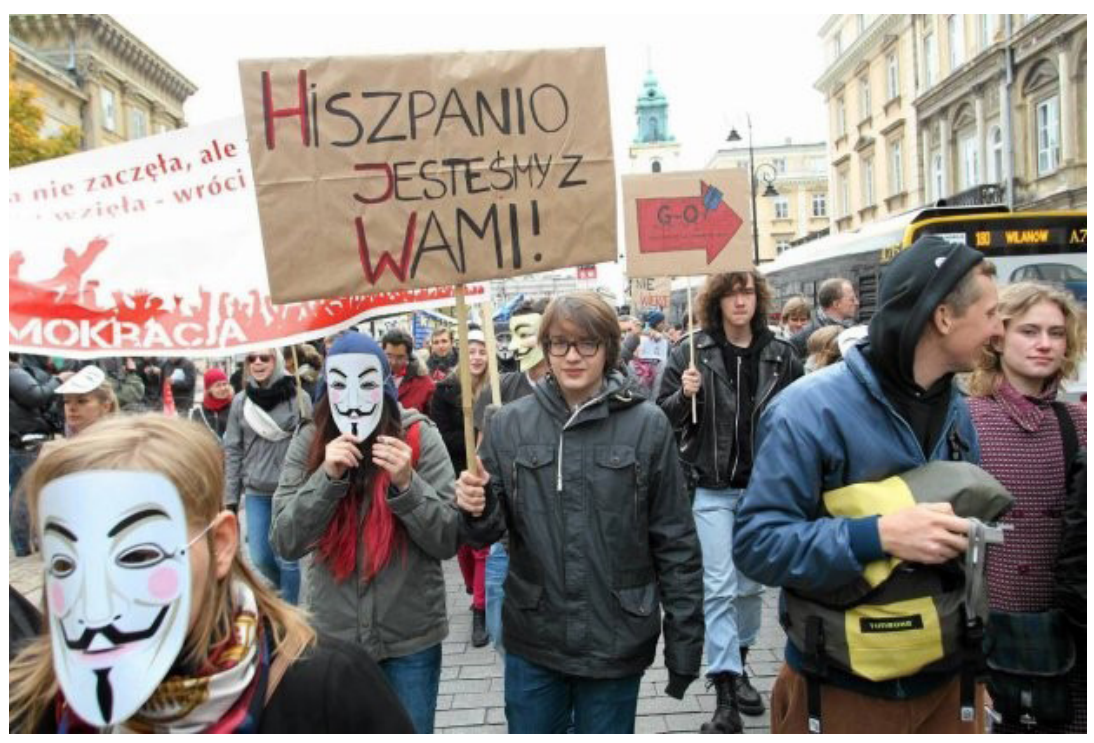

Fotografía 1. Los polacos protestando: "!España, estamos con vosotros!" Fuente: Wojciech Olkuśnik, Agencja Gazeta, gazeta.pl 


\section{Voces críticas: la iniciativa "Indignados con los Indignados" y otros comentarios}

Coetáneamente a la iniciativa de los Indignados polacos surgió una corriente de oposición de nombre provocativo: "Indignados con los Indignados." Los fundadores de este movimiento se definieron como jóvenes racionalistas. En el manifiesto en la red explicaron a sus coetáneos: somos conscientes de que la adolescencia es un período de romanticismo, pero este romanticismo debe ser acompañado por las reglas fundamentales de la racionalidad. Sus acusaciones a los Indignados, demasiado soñadores y reivindicadores, se resumen bien en estas palabras:

Queremos vivir en un país que pueda garantizar un futuro estable y previsible. No se trata del materialismo, pero de un sentido básico de seguridad. En los tiempos de hoy esto no se puede conseguir sin recortes del presupuesto. Somos conscientes de esta situación porque no nos falta la racionalidad. Por eso somos contrarios a la acción de los 'indignados' polacos, que es solo un 'grito sin contenidos'. Las demandas de ellos son, en el mundo de hoy inmerso en la recesión, una utopía (Oburzeni..., 2011).

Los jóvenes racionalistas no fueron los únicos en criticar las protestas en Varsovia. Los comentadores de la vida política y social en Polonia, provenientes de los medios de comunicación de derecha, reprochaban a la iniciativa de los Indignados el caos ideológico, la banalización y la infantilización del debate sobre la situación de los jóvenes en Polonia, su programa utópico. Otros los acusaban de que es una iniciativa "politizada" apoyada por los partidos de izquierda y por los medios de comunicación "izquierdistas" (como "Krytyka Polityczna"14). Uno de los comentaristas definió a la protesta: "la marcha de los hipsters indignados" (Górecki, 2011). En su opinión, las manifestaciones fueron una "expresión del socialismo de mierda nacido de la holgazanería y actitud reivindicativa" (Górecki, 2011). A la iniciativa se le reprochaba también que fue un "producto derivado", copiado sin reflexión de los países occidentales. Hubo quien habló de la "importación de la indignación", de la caricatura de las iniciativas semejantes en el mundo (Radio TOK FM, 2011). Aparecieron términos y expresiones como: una moda, un cliché, gestos rituales sin contenido repetidos sin consciencia. Un periodista constató que la marcha de los indignados polacos fue un "teatrillo izquierdista" (Warzecha 2011; Gursztyn, 2011, Radio TOK FM, 2011; Jarzyński, 2011). Añadió, asimismo, que los verdaderos indignados ni sabían que alguien estaba protestando en su nombre. La siguiente tabla presenta algunos comentarios irónicos de la prensa, especialmente de derecha:

14 "Krytyka Polityczna" [La Crítica Política] - una revista socio-política polaca del ambiente intelectual de izquierda, fundada en 2002 en Varsovia, cf. http://issuu.com/krytykapolityczna/docs/political-critique 
Tabla 3. Ejemplificación de los comentarios sarcásticos de la prensa polaca
"Niños ricos juegan a la revolución"
"Nueva Internacional"
"Jóvenes militantes idealistas de familias varsovianas bien acomodadas"
"Los indignados polacos o sea la revolución de octubre ${ }^{15}$ fracasada"
"¿indignados o aburridos con Starbucks?"
"¿Con qué cosa puede estar indignado un muchacho de 18 años, con un test de matemáticas?"

Fuente: elaboración propia a partir de diferentes artículos de prensa polaca analizada para la investigación

No faltaron en la prensa polaca comentarios más elaborados, en los que los autores intentaban analizar el nuevo movimiento social y sus actores: "Los niños varsovianos "de plátano"16 andan arrastrando los pies de una fiesta a otra meditando sobre cómo debería estar puesto el flequillo en esta temporada: más a la derecha o a la izquierda... o qué color deberían tener las monturas de las gafas. Y luego llega la realidad que les empuja con tanta fuerza que pierden el equilibrio" (Górecki, 2011). Aparecieron descripciones del perfil "izquierdista" de los estudiantes del Instituto Humanístico Multicultural de Varsovia, iniciadores de las protestas: "Quieren ser artistas o intelectuales alternativos, toman fotografías con cámaras fotográficas analógicas, leen poesía de nicho lespecializada, poco conocida, K. G.J, debaten sobre su sexualidad desde la perspectiva freudiana. Algunos de ellos citan a Lenin en sus cuentas de Facebook o de twitter ${ }^{17}$. Pero al mismo tiempo son hijos de padres ricos, de la clase media alta, que puede permitirse una "revuelta festiva" con su dispositivo Apple y una taza de café en la mano" (Jesień oburzonych, 2011). Un comentador constató que el movimiento de los Indignados se parece más a la sección juvenil de un partido de izquierdas que a un movimiento social auténtico. La protesta del día 15 de octubre fue criticada con las siguientes palabras: "La protesta polaca comprendía una cifra 'lamentable' (muy baja) de hipsters y estetas de gran ciudad equipados con iPods parroquianos del local "Un mundo feliz"18 (título del libro de Huxley), gestionado por

15 Por parte de los comentaristas polacos que analizaban la iniciativa varsoviana aparecieron comparaciones a la revolución de octubre mientras que los protestantes de España hacían referencia al contexto francés: un participante de la Acampada de Sol recuerda en su ensayo que durante la protesta se tocó la Marsellesa (Monedero 2011, 81-82).

16 Comparación con la "juventud de plátano" (Bananowa młodzież), un término creado en los años 60 del siglo XX como instrumento de propaganda del gobierno polaco. Se utilizó en referencia a los representantes del ambiente universitario que protestaron contra el acoso antisemita iniciado por las autoridades polacas en1968. Según los exponentes políticos, los jóvenes estudiantes de familias adineradas (en aquel momento el plátano ero un símbolo de bienestar y lujo) no tenían derecho para pronunciarse sobre la situación porque no conocían los verdaderos problemas del ambiente académi$\mathrm{CO}$.

17 Los críticos del Movimiento controlaron la cuenta Facebook del fundador e iniciador de la protesta Grzegorz Janiczak y descubrieron que él mismo se definía como "ateo, libertino, librepensador", contrario a la religión. En su cuenta se encontraban también citaciones de Lenin y de Marx (Leszczyński, 2011).

18 "Nowy Wspaniały Świat" - un local en Varsovia, fundado y gestionado por el ambiente de la revista "Krytyka Polityczna". 
'Krytyka Polityczna', que marchaban por la ciudad gritando eslogancitos anticapitalistas" (Warzecha, 2011).

Otros observadores subrayaban la componente hipócrita de la iniciativa, demostrando que los jóvenes critican el mismo sistema que les permitió el bienestar: "Las demandas de los Indignados muestran que no es un movimiento representativo para toda la sociedad pero reprime deseos de una pequeña parte de los jóvenes de orientación de izquierdas. Los que tienen su bienestar garantizado por sus padres... y los padres lo tienen asegurado gracias al capitalismo tan odiado por los hijos..." (Jesień oburzonych, 2011). Algunos recordaron que la protesta fue organizada por un grupo de jóvenes del instituto privado de Varsovia donde por la matrícula mensual se paga mucho y cuyos alumnos consiguen sin problemas entrar en las universidades estatales polacas, que son las mejores y gratuitas. En los comentarios críticos se repetía una observación: los verdaderos indignados en Polonia no participan en las manifestaciones porque deben pensar en cómo sobrevivir día a día.

\section{Voces entusiastas y la hermandad con los españoles}

Aparecieron asimismo comentarios positivos que resaltaban la importancia del movimiento Indignados polaco. Los entusiastas constataban que es verdad que los sociólogos les llaman "una generación que pone preguntas sin saber cuáles podrían ser las respuestas". Pero al mismo tiempo constituyen una fuerza que puede dejar todo el sistema revuelto. El sistema que debía servir a la gente ha escapado al control y "tomó el poder", dominando a las personas y eso lo constatan los jóvenes. En muchos comentarios se subrayaba la inspiración visiblemente española. Los jóvenes varsovianos protestantes entrevistados para un artículo confesaron que mientras escuchaban a un activista español pensaron "sería muy incomodo si no hubiese ocurrido nada en Varsovia". Entonces prepararon miles de pósteres y salieron a la calle (Janiszewski, 2011). Algunos comentaristas respondieron a las críticas lanzadas por los periodistas de derecha, defendiendo el derecho de los jóvenes a protestar. Explicaban el hecho de que los "Indignados" polacos provengan de familias adineradas no implica que no puedan protestar, que no tienen una autorización moral para manifestarse. Añadían que el Instituto Multicultural debería estar contento de tener tales alumnos y bachillerados que no piensan cómo enriquecerse, sino cómo cambiar el mundo para hacerlo mejor. Quieren ocuparse de los demás en vez de ocuparse de ellos mismos.

Para los entusiastas de la iniciativa, el movimiento de los Indignados polacos fue una manifestación de altruismo y sensibilidad social. En una entrevista titulada "La sociedad se despierta y lucha por sus asuntos" se analizaron las semejanzas entre la situación en España y en Polonia. Se habló de los "precarios ${ }^{19}$ sin futuro" y de "víctimas de las prácticas/ aprendizajes y de los contratos basura" (Sutowski, 2011). El politólogo Michał Sutowski ${ }^{20}$

19 Las palabras prekariusz (precario) y prekariat (precariado) son neologismos que entraron ya en el lenguaje contemporáneo polaco y se radicaron en el vocabulario de los medios de comunicación en la época de las protestas de los Indignados. Pueden ser uno de los ejemplos de la influencia cultural entre España y Polonia.

Michał Sutowski encarga la función del secretario de la Redacción de "Krytyka Polityczna". 
entrevistado en ese artículo enumeró algunos problemas comunes de los jóvenes polacos y españoles: contratos basura, aprendizajes y prácticas sin remuneración, estudios universitarios "engañosos e ilusorios", el paro. Definió el movimiento de los Indignados como una respuesta a la mala distribución de los bienes en la sociedad. El periodista, interesado en las influencias y semejanzas entre la situación en España y en Polonia, puso una pregunta provocante: "¿Cómo es posible que la misma suerte tocó a los perezosos habitantes del Sur y a nuestros laboriosos polacos"?

La respuesta del experto desmanteló los estereotipos sobre el carácter nacional de las dos poblaciones, destacando el problema del sistema, que es muy parecido en dos países: la economía está fundada en costes bajos de trabajo y bajas remuneraciones. Comentó también el papel de los sindicatos, que no se encuentran bien en la nueva realidad capitalista, no consiguen mantener sus funciones, o sea, defender derechos de los trabajadores. Según la opinión del comentador, los sindicados hoy en día no son "sexy", están presentados como grupos de personas agresivas y reivindicativas que no quieren dejar sus posiciones y no saben hacer compromisos. España y Polonia encabezan la lista de los países con más contratos basura, porque las dos son víctimas de la estrategia de la "elasticidad" en el mercado de trabajo, que ha sido divulgada y promocionada durante muchos años. Se esperaba que la flexibilidad liberara las personas de las limitaciones, del sistema opresivo del trabajo, de las estructuras jerárquicas. Pero, al contrario, provocó la falta total de estabilidad y el aumento de la frustración de los trabajadores (Sułkowski, 2011).

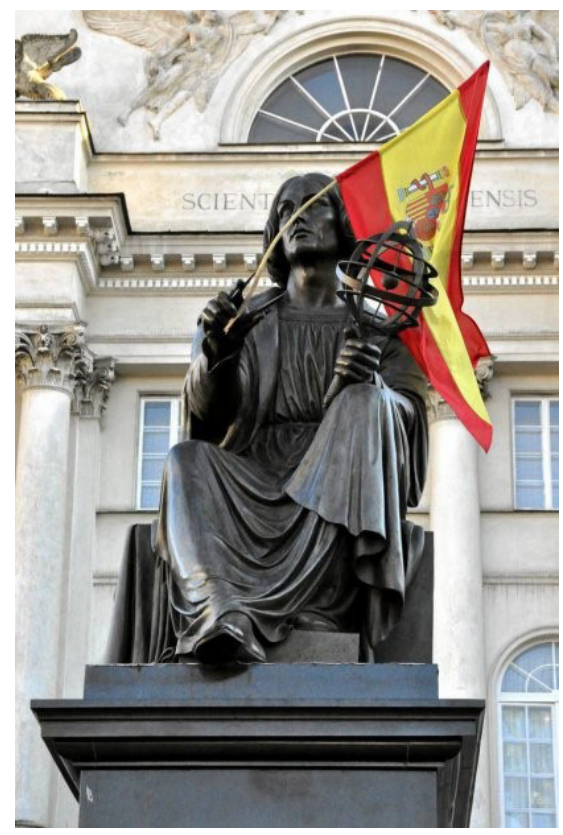

Fotografía 2. Varsovia simpatiza con Madrid: la estatua de Copérnico llevando la bandera española en frente de la Academia Polaca de Ciencias

Fuente: gazeta.pl 


\section{Indignados polacos. ¿Por qué “Indecisos”? Causas del fracaso}

Sería interesante preguntarse sobre por qué las protestas polacas eran de tamaño limitado y por qué aparecieron tan tarde. Los comentaristas identificaron algunas causas de ese fracaso. Una de las razones indicadas fue la consciencia social poco desarrollada en Polonia. La mayoría de los polacos opta por "las estrategias individuales de arreglárselas" y el nivel de confianza es muy bajo, falta la voluntad de cooperación. Hay una impresión de que los polacos prefieran arreglárselas por su cuenta que intentar modificar el sistema. Como subraya Kozłowski, hubo una convicción común en Polonia, después de 1989, que se podía resumir en las siguientes palabras: "si opinas que la culpa sea de este sistema, pues significa que quieres volver al sistema precedente, al comunismo". Esa idea fue tan bien arraigada en la mentalidad de la gente que hasta hoy en día muchos polacos todavía creen que el mal que les está ocurriendo es por culpa de ellos mismos (Kozłowski, 2011). Piotr Ikonowicz, un periodista que durante muchos años era el jefe del Partido Socialista Polaco ${ }^{21}$, constata que el problema principal es "acostumbrarse" a la pobreza. Explica que una conspicua parte de los polacos no se rebela por causa de la vergüenza, decepción, aislamiento (Ikonowicz, 2011).

Parece que también la generación joven ha internalizado esa herencia cultural del sistema comunista. A los jóvenes polacos les faltan la inspiración y el apoyo por parte de las generaciones mayores, tan acostumbradas a la actitud pasiva, resignada a su "pequeña estabilización" sin ulteriores expectativas. Según Karoń, los jóvenes polacos no poseen una visión coherente del futuro ni saben imaginarse un mundo mejor para ellos. Parece provocadora la diagnosis de la sociedad polaca propuesta por el autor: "Preferimos apretar los dientes que luchar por nuestros derechos..." (Karón, 2011). Hubo en la historia de Polonia muchos ejemplos del carácter intransigente de sus habitantes. Numerosas sublevaciones polacas del siglo XIX estuvieron marcadas por inmenso coraje, pero al mismo tiempo por idealismo excesivo y romanticismo utópico. Después de los repartos y de las dos guerras mundiales llegó un siguiente período difícil de afrontar, forzando la gente a inventar soluciones día a día para sobrevivir y buscarse la vida. De todas maneras, la falta del éxito de la iniciativa de los Indignados podría ser consecuencia de una "actitud nacional", radicalizada durante muchos años del sistema opresivo introducido por los soviéticos. El aparato del socialismo real rompió muchos vínculos sociales e instintos sociales que deberían ser naturales en una comunidad. Los polacos solo conocieron dos sistemas en los cuales tuvieron que (y aún deben) existir: el socialismo en su variante autoritaria que rechazaron, y luego el capitalismo feroz, llamado "corporativo", en el que el papel dominante lo juegan las corporaciones burocráticas jerárquicas y que está caracterizado por la existencia de grandes grupos de intereses y de negocios que influencian las políticas del Gobierno.

Los polacos no tuvieron ocasión para conocer el "buen" capitalismo democrático y constructivo (Żakowski, 2011). La falta del interés hacia la iniciativa de los Indignados

21 PPS, Polska Partia Socjalistyczna, un partido que fue fundado en 1987. En el periodo 1988-1990 constituyó una parte de la oposición democrática. Después del 1989 algunas veces consiguió entrar en el parlamento formando un grupo pequeño de representantes. Ahora queda fuera del parlamento. 
en Polonia puede derivar del "profundo y patológico individualismo de los polacos", que se ha radicalizado e interiorizado después de 1989 (Sutowski, 2011). Durante muchos años de socialismo real los polacos aprendieron cómo engañar al sistema (es decir, a las autoridades), pero no descubrieron cómo utilizarlo para lograr sus objetivos. Diferentes maneras de arreglárselas y el arte de adaptarse han sido durante demasiado tiempo unas de las características principales de los polacos. Y esa estrategia, bien elaborada, ha sido transmitida a los jóvenes. Actualmente muchos polacos se dan cuenta de estar mal, pero muchas veces no hacen nada constructivo. Algunos emigran, otros esperan en silencio y soportan las incomodidades por el miedo de perder el statu quo, poco satisfactorio, pero por lo menos conocido y relativamente estable (Sutowski, 2011).

\section{Conclusión -El coraje de la generación perdida-}

Las estadísticas y los números desvelaron brutalmente la falta del interés y la poca aportación de los polacos a las protestas de los Indignados. No obstante, vale la pena recordar que la dimensión cuantitativa es solo uno de los criterios según los cuales se podría evaluar esa iniciativa. En el aspecto cualitativo, parece incuestionable la importancia del movimiento y el compromiso con el cual los jóvenes alumnos intentaron sumarse a las protestas de alcance mundial. El Acuerdo del 15 de Octubre fue creado con la iniciativa de los alumnos del Instituto Humanístico Multicultural de Varsovia como signo de la solidaridad con el movimiento de los Indignados en España y, al mismo tiempo, para presentar sus propias demandas a las autoridades polacas (Dąbrowski, 2011). En el texto de su manifiesto los Indignados polacos explicaron sus intenciones: "durante mucho tiempo hemos creído que ellos quieren cambiar la realidad. Ahora somos indignados. Porque sabemos que los gobiernos no escuchan la voz de la sociedad, que actúan en desfavor de nosotros. Somos indignados con las mentiras y la ignorancia que hay en el parlamento. Somos indignados con la situación actual en Polonia" (PAP, 2011).

A esa constatación de carácter genérico se unieron opiniones individuales de los protestantes, publicadas en varios artículos de prensa. Uno de los indignados se quejó: "Para poder estudiar debo trabajar 10 hora al día. Incluso si termino buenos estudios y obtengo una licenciatura, el único trabajo posible será con el contrato basura. Queremos tener enfrente un futuro, aunque muchos nos definan como generación perdida" (Janiszewski, 2011). Agnieszka Sowa define a este grupo de jóvenes "generación de antesala" (Sowa, 2011), especificando que se trata de unos 6 millones de polacos entre 19 y 29 años. La periodista recordó que en 2011 los jóvenes en Polonia pertenecientes a la categoría NEETS ${ }^{22}$ constituían un casi 12 \% (Sowa, 2011). Las personas jóvenes en paro constituyen un verdadero problema social. En un artículo titulado "El ejército de millones de jóvenes sin trabajo" (Pawłowska-Salińska y Piątkowska, 2012) fueron presentados resultados de una investigación sobre el paro entre los jóvenes en Polonia, realizada por Instituto de Asuntos Públicos en 2012. El análisis demostró que su situación está empeorándose más

$22 \quad$ Not in Education, Employment or Training 
rápido que la condición de sus coetáneos en otros países europeos. Crece el número de los desocupados con edad por debajo de 24 años.

El número de contratos basura es casi el más alto en Europa. La edad media en Europa para comenzar a trabajar son 20 años, y en Polonia, 22. Los jóvenes polacos que habían emigrado a España, Irlanda o Gran Bretaña ahora regresan a una patria aumentando la cifra de los jóvenes en paro. En 2012 una de cada dos personas desocupadas que se registraron en la oficina de empleo tenía menos de 34 años. El porcentaje de las personas en paro hasta 24 años en Polonia (entre 48 y 57 \% dependiendo de la región) era tres veces más alto que el porcentaje de la desocupación general en Polonia. Del estudio resultó que los empleadores no les ofrecen trabajo porque tienen miedo de su alta rotación (mudan de lugar con mucha frecuencia) y por falta de experiencia. El resultado es alarmante: aparecen más contratos basura ${ }^{23}$ y mucho trabajo sumergido (Pawłowska-Salińska y Piątkowska, 2012).

Los alumnos del Instituto Humanístico Multicultural de Varsovia decidieron salir a la calle, pero muchos jóvenes polacos no tienen tiempo para la rebelión. No tienen visión de por qué luchar, ni saben cómo definir su objetivo porque toda su energía la están gastando en "arreglárselas", hacer "chanchullos" para conseguir un trabajo cualquiera. La siguiente opinión de un joven polaco muestra el nivel de la frustración: "Me desacostumbré a pensar sobre el futuro porque no tengo tiempo para eso. Me concentro en sobrevivir día a día" (Janiszewski, 2011). Algunos expertos del mercado de trabajo no pierden la esperanza, convencidos de que "los Indignados son para recuperar" y piden que se les ayude (). GW. Se comportan así porque son "hijos de los tiempos en que vivimos: más atraídos por el éxito y por el placer, que por el esfuerzo". Según el comentarista, la culpa de esta situación sería más bien de los adultos que les han decepcionado. La solución que proponen para "recuperar a los Indignados" es la de promocionar la actividad empresarial de los jóvenes (Pawłowska-Salińska y Piątkowska, 2011). En el contexto polaco parece también válida la observación que se hizo en referencia a las protestas en España: sabrán salir de la crisis solo las sociedades que invierten en sus jóvenes, en desarrollo y en innovación (Feixa 2013, 72). Lo difícil es que nadie consigue presentar una receta para poner estos eslóganes en práctica.

Los más jóvenes que están "hartos con tenerse quietos" (Janiczak, 2011) a menudo irritan a la generación más vieja (X generation), que hoy en día tiene 30 años y más. ¿El contrato fijo, la casa y el seguro son verdaderamente unas reivindicaciones? ¿ ¿ es una normalidad? Para los de 30 años exigir un contrato a tiempo indeterminado durante los estudios puede parecer un capricho, una exigencia excesiva. La perspectiva de la más reciente "Y generation" es diferente. Como explica Nowak, los que tienen hoy 30 años se

23 Vale la pena recordar que en muchos comentarios de prensa el precariado fue presentado como un fenómeno general, no solamente de los jóvenes. La categoría "precarios" se está ampliando en Polonia, y contratos basura alcanzan a diferentes grupos de edad y varios ambientes laborales: gente mayor y de edad media, mujeres que hacen limpieza, cajeras, enfermeras, profesores, negociantes, obreros de varios tipos, etc. (Cf. Janiczak, 2011; Sutkowski, 2011) 
dejaron engañar por el sistema mientras los de 20 años ya no lo quieren repetir (Karpieszuk, 2011). Una conclusión de este breve ensayo puede contenerse en las palabras animosas de Grzegorz Janiczak, uno de los iniciadores de la protesta de los Indignados polacos: "No queremos gritar, queremos conversar. Que las autoridades dejen de tratarnos como una mercancía y de limitar todo a la dimensión económica, consumista. Que comiencen a hablar con nosotros y tener en consideración nuestras opiniones. Dejad de persuadirnos que después el 1989 no tenemos ya nada contra qué protestar" (Janiczak, 2011).

\section{Referencias bibliográficas}

Castells, M. (2009). The Power of Identity: The Information Age: Economy, Society, and Culture Volume II. Chichester: Wiley-Blackwell.

Della Porta, D. y Diani, M. (2009). Ruchy społeczne. Wprowadzenie. Kraków: Wydawnictwo Uniwersytetu Jagiellońskiego.

Feixa, C. y Nofre, J. (2013). Generación Indignada. Topías y Utopías del 15M. Lleida: Editorial Milenio.

Feixa, C. (2013). Crónicas del 15M: Del campamento al ágora. En C. Feixa y J. Nofre (Ed.) Generación Indignada. Topías y Utopías del 15M. Lleida: Editorial Milenio.

Fernández -Planells, A. (2013). \#acampadabcn: El 15M desde Catalunya. En C. Feixa y J. Nofre (Ed.) Generación Indignada. Topías y Utopías del 15M. Lleida: Editorial Milenio.

Giménez Chueca, I. (2011). "Democracia Real Ya" entre el Open Government y el ciberactivismo. En AA. V., La rebelión de los Indignados. Madrid: Editorial Popular.

Golemo, K. (2012). Entre poder y espectáculo. Nuevas dimensiones de la cultura política en Polonia. En "Documentos de Trabajo Seminario Permanente de Ciencias Sociales", número 7, año 2012. ISSN 1887-3464 (ed. CD-ROM) 1988-1118 (ed. en línea)

Manifiesto "iDemocracia Real, Ya!" (2011). En AA. W: La rebelión de los Indignados. Madrid: Editorial Popular.

Mondero, J. C. (2011). La Marsellesa en la Puerta del Sol. En AA. VV: La rebelión de los Indignados. Madrid: Editorial Popular.

Paleczny, T. (2010). Nowe ruchy społeczne. Kraków: Wydawnictwo Uniwersytetu Jagiellońskiego.

Słownik socjologii i nauk społecznych (2008). Warszawa: PWN.

Toscano, V. Vanesa (2013). Testimonio en primera persona desde la Ciudad del Sol. En C. Feixa y J. Nofre (Ed.) Generación Indignada. Topías y Utopías del 15M. Lleida: Editorial Milenio.

Touraine, A. (2005). Un nouveau paradigme. Pour comprendre le monde aujourd'hui. Paris: Librairie Arthème Fayard.

Artículos de prensa polaca utilizados para el análisis, y citados en el texto

Dąbrowski, M. (2011). Polscy oburzeni też protestują, "Rzeczpospolita" 15.10.2011. Recuperado el 10 de diciembre de 2013. Disponible en: http://www.rp.pl/artykul/733345.html

Górecki, M. (2011). Marsz oburzonych hipsterów, Salon 24. Niezależne Forum Publicystyczne 18.10.2011. Recuperado el 15 de diciembre de 2013. Disponible en: http://oburzeninaoburzonych.salon24. pl/355454,michal-gorecki-marsz-oburzonych-hipsterow 
Gursztyn, P. (2011). Bogate dzieciaki bawią się w rewolucję, "Rzeczpospolita” 16.10.2011. Recuperado el 15 de diciembre de 2013. Disponible en: http://www.rp.pl/artykul/733826.html

Ikonowicz, P. (2013). Dlaczego się nie buntujemy, „Rzeczpospolita” 11.04.2013. Recuperado el 15 de diciembre de 2013. Disponible en: http://www.rp.pl/artykul/999104.html

Janiszewski, B. (2011). Polscy "oburzeni" czyli nieudana rewolucja październikowa, "Newsweek" 18.10.2011. Recuperado el 10 de diciembre de 2013. Disponible en: http://www.newsweek.pl/ polscy--oburzeni---czyli-nieudana-rewolucja-pazdziernikowa,83431,1,1.html

Jesień oburzonych (2011). Salon 24. Niezależne Forum Publicystyczne, 25.10.2011. Recuperado el 11 de diciembre de 2013. Disponible en: http://oburzeninaoburzonych.salon24.pl/357464,jesienoburzonych

Karpieszuk, W. (2012) Miasteczko oburzonych w centrum Warszawy. Zobacz gdzie, "Gazeta Wyborcza” 24.05.2012. Recuperado el 12 de diciembre de 2013. Disponible en:http://warszawa.gazeta.pl/wa rszawa/1,34889,11795213,Miasteczko_oburzonych_w_centrum_Warszawy_Zobacz_gdzie.html

Karpieszuk, W. (2011). Młodzi oburzeni wyjdą na ulicę. Już w sobotę marsz, „Gazeta Wyborcza” 14.10.2011. Recuperado el 10 de diciembre de 2013. Disponible en:http://warszawa.gazeta.pl/war szawa/1,34889,10468355,Mlodzi_oburzeni_wyjda_na_ulice_Juz_w_sobote_marsz.html

Konarski, Ł. (2011). "Oburzeni” w Warszawie? Przyszło tylko 100-200 osób, „Gazeta Wyborcza” 15.10.2011. Recuperado el 15 de diciembre de 2013. Disponible en:http://wiadomosci.gazeta.pl/ wiadomosci/1,114873,10475410,_Oburzeni_w_Warszawie_Przyszlo_tylko_100_200_osob_html

Janiczak, G. lentrevista] (2011). Mamy dość siedzenia cicho, „Krytyka Polityczna” 14.10.2011. Recuperado el 15 de diciembre de 2013. Disponible en: http://www.krytykapolityczna.pl/Wywiady/ JaniczakMamydoscsiedzeniacicho/menuid-431.html

Jarzyński, W. (2011). Importowanie „oburzenia”, mojeopinie.pl, 15.10.2011. Recuperado el 15 de diciembre de 2013. Disponible en http://www.mojeopinie.pl/importowanie_oburzenia,3,1318679668

Karoń, T. [entrevista] (2011). Nie mają czasu na bunt, „Moja Wyspa”, 24.05.2011. Recuperado el 15 de diciembre de 2013. Disponible en http://www.mojawyspa.co.uk/artykuly/27869/Nie-maja-czasu na-bunt

Kozłowski, P. [entrevista] (2011). Prof. Kozłowski: Oburzeni odpowiedzą na fatalny podział dochodów, „Newsweek" 17.10.2011. Recuperado el 15 de diciembre de 2013. Disponible en http://polska. newsweek.pl/prof--kozlowski- - oburzeni- odpowiedzia-na-fatalny-podzial-dochodow,83454,1,1. html

Leszczyński, A. (2011). Te okropne bogate dzieciaki, „Gazeta Wyborcza” 17.10.2011. Recuperado el 16 de diciembre de 2013. Disponible en: http://wyborcza.pl/1,113922,10481810,Te_okropne_ bogate_dzieciaki.html

Oburzeni na oburzonych. Młodzi-racjonalni. Salon 24. Niezależne Forum Publicystyczne 13.10.2011 Recuperado el 17 de diciembre de 2013. Disponible en. http://oburzeninaoburzonych.salon24. pl/354078,oburzeni-na-oburzonych-mlodzi-racjonalni

Opolska, K. (2011). „Marsz Oburzonych” w Warszawie. „Wypowiadamy się w imieniu 30 milionów”, „Gazeta Wyborcza”, 14.10.2011. Recuperado el 17 de diciembre de 2013. Disponible en: http:// wiadomosci.gazeta.pl/wiadomosci/1,1 14873,10469144,_Marsz_Oburzonych_w_Warszawie Wypowiadamy_sie_w.html 
PAP: Warszawa. Kilkaset osób uczestniczyło w marszu „oburzonych” (2011), „Gazeta.pl” 15.10.2011. Recuperado el 17 de diciembre de 2013. Disponible en: http://wiadomosci.gazeta.pl/wiadomos ci/1,114873,10476469,Warszawa_Kilkaset_osob_uczestniczylo_w_marszu_oburzonych_html

Pawłowska-Salińska, K. y Piątkowska, M. (2011). Oburzeni są do odzyskania. Pomóżmy im, „Gazeta Wyborcza" 25.11.2011. Recuperado el 17 de diciembre de 2013. Disponible en: http://wyborcza. pl/1,76842,10705787,Oburzeni_sa_do_odzyskania_Pomozmy_im.html

Pawłowska-Salińska, K. y Piątkowska, M. (2012). Milionowa armia młodych bez pracy, „Gazeta Wyborcza" 8.10.2012. Recuperado el 17 de diciembre de 2013. Disponible en: http://wyborcza. pl/1,76842,12626158,Milionowa_armia_mlodych_bez_pracy.html

Radio TOK FM: programa de la mañana del 14.10.2011. Recuperado el 16 de diciembre de 2013. Disponible en: http://wiadomosci.gazeta.pl/wiadomosci/1,1 14873,10469158,Lis_Wladyka_i_ Wolek_nie_ida_na_Marsz_Oburzonych_html

Sowa, A. (2013). Pokolenie poczekalni, „Polityka” 9.07.2013. Recuperado el 17 de diciembre de 2013. Disponible en: http://www.polityka.pl/spoleczenstwo/artykuly/1548373,1,oszukanidwudziestolatkowie.read

Sutowski, M. [entrevista] (2011). Społeczeństwo się budzi i walczy o swoje, „MM Moje Miasto”. Recuperado el 15 de diciembre de 2013. Disponible en: http://www.mmsilesia.pl/389844/201 1/10/14/ spoleczenstwo-sie-budzi-i-walczy-o-swoje?category=magazyn

Warzecha, Ł. (2011). Polscy „oburzeni” czyli troski hipsterów, „Fakt” 17.10.2011. Recuperado el 10 de diciembre de 2013. Disponible en: http://www.fakt.pl/Warzecha-Polscy-oburzeni-czyli-troskihipsterow,artykuly, 133912,1.html

Żakowski, J. (2011). Dlaczego milczymy, „Gazeta Wyborcza” 17.10.2011. Recuperado el 17 de diciembre de 2013. Disponible en: http://wyborcza.pl/1,76842,10479765,Dlaczego_milczymy.html 